\title{
Analisis Bibliometrik Terhadap 40 Publikasi Tentang Airtanah di Cekungan Bandung
}

Muhammad Malik Ar Rahiem

M.Sc Programme Tropical Hydrogeology and Environmental Engineering TU Darmstadt, Germany

Malikarrahiem91@gmail.com

\begin{abstract}
Abstrak
Analisis bibliometrik dilakukan terhadap 40 publikasi tentang air tanah di Cekungan Bandung yang berada dalam basis data Web of Science. Analisis yang dilakukan yaitu analisis Co-Authorship dan analisis TextMining menggunakan metode perhitungan biner dan perhitungan penuh menggunakan piranti lukan VosViewer. Terdapat 125 penulis dan 1296 kata/istilah yang muncul dan kemudian menjadi dasar analisis. Hasil dari analisis ini menunjukkan bahwa riset air tanah di Cekungan Bandung dapat dibagi menjadi dua kelompok besar, yaitu kelompok penurunan muka tanah dan kelompok air tanah secara umum. Kelompok air tanah dapat dibagi lagi menjadi 3 kelompok kecil, yaitu kelompok pemodelan akuifer, pemodelan kontaminasi, dan pemodelan pencampuran air tanah. Analisis bibliometrik sangat membantu dalam memetakan perkembangan penelitian di Cekungan Bandung. Meski demikian masih banyak kekurangan dari hasil analisis bibliometrik, terutama karena terbatasnya metadata publikasi yang ada dalam basis data Web of Science. Ke depannya, metadata publikasi lain, terutama dari Google Scholar perlu dikonversi ke dalam templat yang bisa dianalisis menggunakan metode bibliometrik.
\end{abstract}

Kata kunci: Bibliometrik, airtanah, Cekungan Bandung

\section{Latar Belakang}

Sudah banyak riset yang membahas mengenai air dan air tanah di kawasan Cekungan Bandung. Riset-riset yang telah dipublikasikan sangat beragam, berasal dari banyak disiplin ilmu, dan telah ada sejak puluhan tahun yang lalu.

Salah satu cara untuk menarik garis besar dari begitu banyak publikasi yang ada adalah dengan melakukan studi bibliometrik. Dalam studi bibliometrik, digunakan metode statistik untuk menganalisis metadata publikasi yang tersedia dalam basis data publikasi yang dikembangkan oleh banyak lembaga di dunia ini. Basi data ini beberapa bisa diakses gratis, beberapa harus berlangganan.

Dalam basis data ini, setiap metadata publikasi terdiri atas data judul, pengarang, abstrak, kata kunci, referensi, jurnal tempat makalah dipublikasikan, negara masing-masing penulis, instansi tempat masingmasing penulis bekerja, dan banyak data lainnya. Studi bibliometrik biasanya digunakan untuk mengevaluasi kinerja universitas, lembaga riset, atau peneliti. Meski demikian, studi ini juga bisa digunakan untuk memahami bagaimana struktur suatu bidang ilmu, atau bagaimana perkembangan riset topik-topik tertentu (Waaijer \& Palmblad, 2015).

Dalam makalah ini, analisis bibliometrik dilakukan terhadap data publikasi mengenai airtanah di Cekungan Bandung. Basis data publikasi yang digunakan adalah basis data Web of Science (WoS). WoS adalah suatu basis data bibliografik yang dikembangkan oleh penerbit Thomson Reuters. WoS menyimpan data-data publikasi dari lebih 33.000 jurnal, sehingga basis datanya merupakan salah satu yang paling sering 
digunakan untuk studi bibliografi. Basis data lain yang bisa digunakan antara lain; Dimensions, Scopus, Pubmed, RIS, dan Crossref.

Meski dasar dari studi bibliometrik adalah ilmu statistik, yang mungkin cukup menyulitkan bagi mereka yang kurang memiliki latar belakang statistik, namun sekarang sudah banyak aplikasi yang telah dikembangkan dan tersedia gratis, sehingga semua orang bisa melakukan studi bibliometrik. Salah satu aplikasi yang cukup terkenal dikembangkan oleh Nees Jan van Eck dan Ludo Waltman dari Universitas Leiden, yaitu VosViewer (van Eck \& Waltman, 2010). VosViewer merupakan singkatan dari Visualizations of similarities atau visualisasi kemiripan. VosViewer telah digunakan dalam sangat banyak studi (https://www.vosviewer.com/publications), sehingga metodenya cukup teruji.

\section{Data dan Metodologi}

Berdasarkan pencarian laman Web Of Science dengan kata kunci "Bandung" sebagai topik dan "groundwater" juga sebagai topik, dengan jangka waktu pencarian sejak 1945 hingga 2019, didapatkan hasil 40 makalah. Makalah paling awal dipublikasikan tahun 1976, dan terbaru tahun 2019.

Jumlah pencarian ini relatif sedikit jika dibandingkan dengan pencarian menggunakan Google Scholar yang menghasilkan jumlah publikasi 2280. Juga lebih sedikit dibandingkan pencarian menggunakan Dimensions yang menghasilkan jumlah publikasi 59. Meski demikian, sumber data dari WoS digunakan, karena metadata hasil pencarian dapat langsung dianalisis dengan mudah menggunakan VosViewer. Untuk data Google Scholar, proses menyiapkan data harus dilakukan manual dan membutuhkan waktu kerja yang cukup banyak. Untuk data dari Dimensions, metadata bisa langsung diproses menggunakan VosViewer, tetapi metadata yang ada tidak cukup lengkap (tidak tersedia abstrak).

Data hasil pencarian ini kemudian dianalisis menggunakan piranti lunak VosViewer. Ada dua analisis yang dilakukan, yaitu analisis Co-authorship dan Text-Mining. Hasil dari kedua analisis ini adalah peta visualisasi bibliometrik. Saat ini VosViewer hanya mampu menganalisis kata dan istilah dalam bahasa Inggris.

Analisis Co-Authorship adalah analisis keterkaitan makalah berdasarkan jumlah makalah yang ditulis bersama. Semakin dekat titik antar penulis, maka semakin banyak penulis tersebut menulis bersama.

Analisis Text-Mining adalah analisis kemunculan suatu kata/istilah yang divisualisasikan dalam suatu peta kehadiran kata. Dalam analisis ini metode perhitungan kata yang digunakan adalah metode biner dan metode full counting. Metode biner berarti hanya kemunculan atau ketidakmunculan suatu kata/istilah yang dihitung, tidak peduli berapa kali kata tersebut muncul di dalam makalah. Sementara metode fullcounting berarti jumlah kemunculan kata dalam makalah dihitung.

Kedua analisis ini kemudian dibandingkan hasilnya. Beberapa makalah penting di setiap kluster hasil analisis ditelaah abstrak dan isinya untuk kemudian disarikan sebagai bahan kajian literatur publikasi airtanah di Cekungan Bandung dan dibahas di dalam diskusi.

\section{Hasil dan Analisis}

Hasil analisis Co-Authorship pada Hasil Pencarian didapatkan 125 nama penulis. Batas ambang minimal publikasi setiap penulis adalah 2 makalah. Terdapat 25 penulis yang termasuk dalam batas ambang. Dari analisis ini didapatkan lima kluster dengan kode warna merah, biru, hijau, kuning, dan ungu (Gambar 1). 


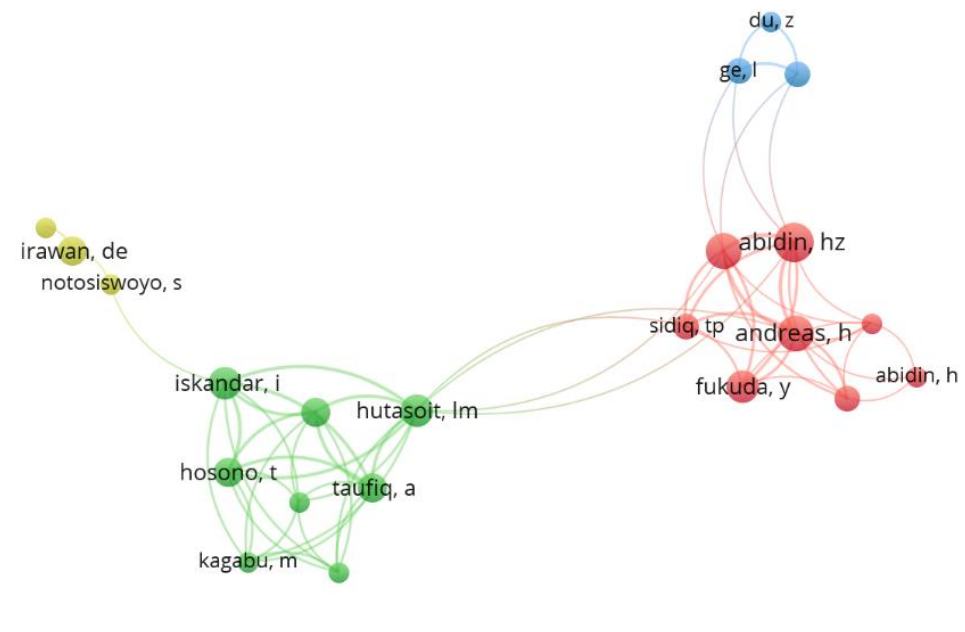

Gambar 1 Hasil analisis VosViewer menggunakan metode Co-Authorship menghasilkan 2 kluster besar, 2 kluster satelit, dan 1 kluster terpisah. Kluster berwarna merah merupakan kelompok penulis riset penurunan muka tanah, dengan kluster berwarna biru sebagai kluster satelitnya. Kluster berwarna hijau merupakan kelompok penulis riset air tanah dengan kluster berwarna kuning sebagai kluster satelitnya. Kluster berwarna ungu terpisah.

Dari Gambar 1 di atas, teramati 2 kelompok besar, 2 kelompok satelit, dan 1 kelompok terpisah dalam riset air tanah di Cekungan Bandung. Kelompok pertama berwarna merah, terdiri atas 7 penulis; Abidin, Andreas, Fukuda, Gamal, Gumilar, Murdohardono, dan Sidiq. Penulis-penulis ini dikenal karena publikasinya di bidang penurunan muka tanah di Cekungan Bandung. Publikasi penting yang ditulis dalam kelompok ini di antaranya: Land subsidence in Bandung Basin and its possible caused factors (Gumilar dkk., 2015), Sinking cities in Indonesia: ALOS PALSAR detects rapid subsidence due to groundwater and gas extraction (Chaussard, Amelung, Abidin, \& Hong, 2013), On causes and impacts of land subsidence in Bandung Basin, Indonesia (Abidin, Gumilar, Andreas, Murdohardono, \& Fukuda, 2013), dan Land Subsidence Characteristics of Bandung Basin (Indonesia) between 2000 and 2005 as Estimated from GPS Surveys (Abidin, Andreas, Gamal, \& Darmawan, 2006).

Kemudian kelompok satelitnya adalah kelompok berwarna biru, dengan 3 orang penulis yaitu, Du, Ge, dan Ng. Publikasi dari kelompok ini adalah Correlating the subsidence pattern and land use in Bandung, Indonesia with both Sentinel-1/2 and ALOS-2 satellite images (Du dkk., 2018) dan Land subsidence characteristics of Bandung Basin as revealed by ENVISAT ASAR and ALOS PALSAR interferometry (Ge, Ng, Li, Abidin, \& Gumilar, 2014).

Kemudian kelompok berwarna hijau dengan 8 orang penulis, yaitu Efendi, Hosono, Hutasoit, Ide, Iskandar, Kagabu, Shimada, dan Taufiq. Penulis-penulis ini terutama dikenal sebagai ahli hidrogeologi. Makalahmakalah dalam kelompok ini di antaranya: Controlling factors and driving mechanisms of nitrate 
contamination in groundwater system of Bandung Basin, Indonesia, deduced by combined use of stable isotope ratios, CFC age dating, and socioeconomic parameters (Taufiq, Effendi, Iskandar, Hosono, \& Hutasoit, 2019), Estimating Groundwater Mixing Ratios from Vertical Flux Processes due to Excessive Groundwater Pumping Using Hydrogeochemical Parameters and Nitrate Concentrations in the Bandung Basin, Indonesia (Taufiq, Hosono, Iskandar, Jatnika Effendi, \& Maringan Hutasoit, 2018), Impact of excessive groundwater pumping on rejuvenation processes in the Bandung basin (Indonesia) as determined by hydrogeochemistry and modeling (Taufiq, Hosono, Ide, dkk., 2018), Groundwater and solute transport modeling at Hyporheic zone of upper part Citarum River (Iskandar, Farazi, Fadhilah, Purnandi, \& Notosiswoyo, 2017), dan Kondisi Permukaan Air Tanah dengan dan tanpa peresapan buatan di daerah Bandung: Hasil Simulasi Numerik (Hutasoit, 2009),

Sementara kelompok satelitnya yang berwarna kuning terdiri atas 3 penulis, yaitu: Irawan, Notosiswoyo, dan Darul. Ketiganya juga dikenal sebagai ahli hidrogeologi. Beberapa makalah dalam kelompok ini di antaranya: Conceptual model of groundwater and river water interactions in Cikapundung riverbank, Bandung, West Java (Achmad Darul, Irawan, Trilaksono, Pratama, \& Fitria, 2016) dan Groundwater and river water interaction on Cikapundung River: Revisited (A. Darul, Irawan, \& Trilaksono, 2015).

Kelompok yang terpisah, terdiri atas tiga penulis; Pangaribuan, Mohammad, dan Muttaqin yang ketiganya menulis bersama makalah tentang air tanah di kawasan Jatinangor, Sumedang.

Selanjutnya pada analisis Text-Mining dengan metode biner, didapatkan 1296 kata/istilah dengan batas minimal kemunculan setiap kata diatur 5 kali, maka didapatkan 41 kata yang termasuk dalam batas ambang (Gambar 2).

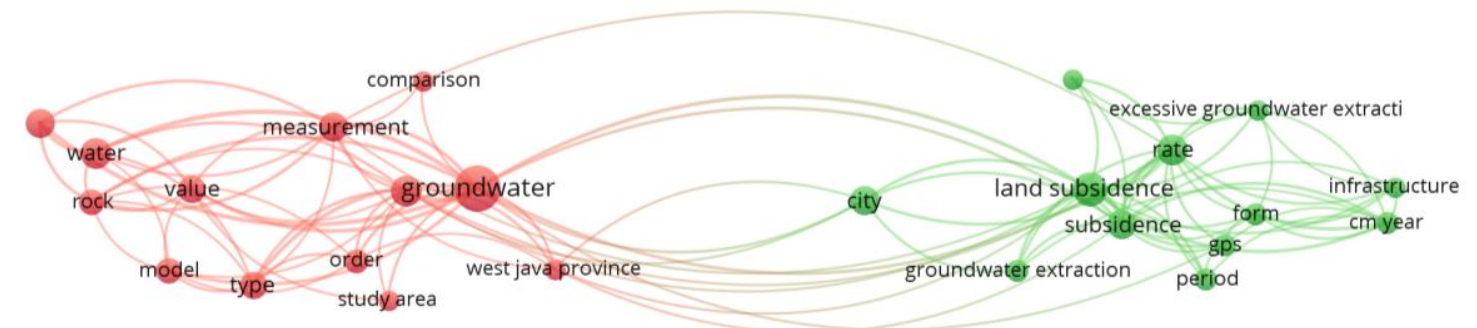

VOSviewer

Gambar 2 Hasil analisis Text Mining menggunakan metode penghitungan biner menghasilkan dua kluster besar yang diinterpretasi sebagai dua kelompok riset utama airtanah di Cekungan Bandung.

Hasil dari analisis ini kurang lebih serupa dengan hasil analisis Co-Authorship. Secara umum penelitian air tanah di Cekungan Bandung dapat dibagi menjadi dua kelompok besar, yaitu kelompok riset air tanah (ditandai dengan warna merah) dan kelompok riset penurunan muka tanah (ditandai dengan warna hijau). Kata kunci yang paling banyak muncul (ditandai dengan ukuran titik yang lebih besar) terutama 
"Groundwater", "Measurement" di kelompok merah. Sementara di kelompok hijau terutama "Land Subsidence", "Groundwater Extraction", "Excessive Groundwater Extraction".

Sedangkan pada analisis text mining menggunakan metode full counting, terdapat $1296 \mathrm{kata} /$ istilah. Batas minimal kata disebut diset 5 kali dan didapatkan hasil 72 kata memenuhi batas ambang, kemudian hanya kata-kata yang relevan dipilih dan terdapat 43 kata yang dikelompokkan ke dalam 5 kluster (Gambar 3).

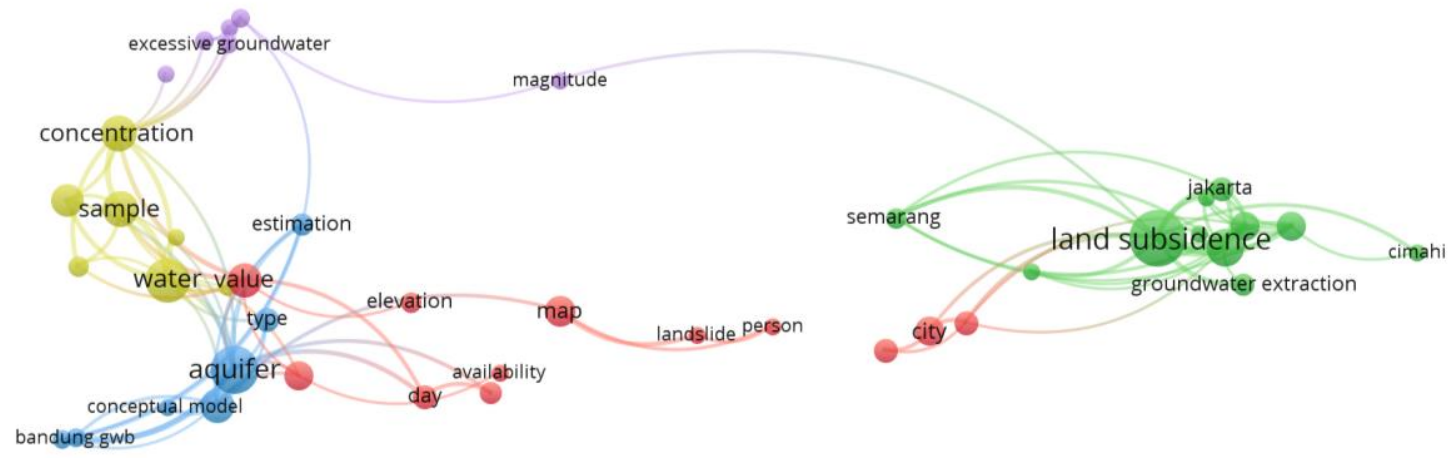

VOSviewer

Gambar 3 Hasil analisis Text Mining menggunakan metode penghitungan full counting menghasilkan 5 kluster. Kluster berwarna hijau merupkan kelompok riset penurunan muka tanah, sementara kluster berwarna biru, kuning, dan ungu merupakan kelompok riset air tanah. Kluster berwarna merah merupakan terminologi-terminologi umum.

Hasil analisis metode full counting menunjukkan pengelompokkan yang lebih majemuk. Pada kluster 1, ditandai dengan warna merah, kata-kata yang termasuk dalam kelompok ini cenderung kata-kata yang umum dan tidak spesifik, seperti "availability", "bandung city", "day" dll. Pada kluster 2, ditandai dengan warna hijau, beberapa kata spesifik muncul seperti "Iand subsidence", "groundwater extraction", "rate", "Jakarta", "Semarang", "Cimahi" mengindikasikan bahwa kluster ini mewakili kelompok riset penurunan muka tanah. Kluster 3 yang ditandai dengan warna biru merupakan kluster yang mewakili kelompok riset air tanah ditandai dengan kata/frasa "conceptual model", "aquifer", "bandung gwb". Kluster 4, ditandai dengan warna kuning juga termasuk kelompok riset air tanah, namun lebih spesifik di bidang kualitas air, kontaminasi dengan kata kunci "concentration", "contamination", "sample". Sementara kluster 5, ditandai dengan warna ungu, juga termasuk kelompok riset air tanah, ditandai dengan kata kunci " $c f c$ ", "deep groundwater", "total mixing ratio".

\section{Diskusi}

Berdasarkan analisis bibliometrik dari 40 makalah yang terindeks dalam basis data Web of Science, dapat dilihat bagaimana riset air tanah di Cekungan Bandung berkembang. Riset air tanah di Cekungan Bandung secara umum dapat dibagi menjadi dua kelompok besar, yaitu riset air tanah dan riset penurunan muka tanah akibat eksploitasi air tanah. Kedua kelompok riset ini, meski juga saling berhubungan, menunjukkan pengelompokkan yang cukup signifikan. 
Dengan metode perhitungan full counting kita bisa membagi kelompok riset air tanah ke dalam beberapa kelompok kecil; pemodelan akuifer, pemodelan kontaminasi, dan pemodelan pencampuran air tanah. Sementara kelompok riset penurunan muka tanah cenderung tetap merupakan satu kelompok besar.

Metode penelitian air tanah pada kelompok air tanah terutama analisis hidrokimia dan isotop, pemodelan hidrogeologi, analisis geofisika. Sementara pada kelompok penurunan muka tanah akibat eksploitasi air tanah umumnya menggunakan metode penginderaan jauh, terutama yang berbasis radar (ENVISAT, ALOS, Sentinel-1) dan metode GPS.

Kedua kelompok besar riset ini juga saling berkolaborasi dicirikan garis yang menghubungkan kedua kelompok ini pada peta. Garis ini terutama menghubungkan Hutasoit dengan Abidin dan Andreas, yaitu pada makalah yang mereka tulis bersama: Land Subsidence in Bandung Basin and its Possible Caused Factors (Gumilar dkk., 2015).

Berdasarkan publikasi-publikasi yang ada, permasalahan air tanah di Cekungan Bandung dapat diringkas sebagai berikut: Ekstraksi air tanah berlebih yang telah dilakukan selama beberapa dekade telah menimbulkan permasalahan. Hutasoit (2009) menyimulasikan kondisi air tanah pada tahun 2013 dengan beberapa skenario. Hasil simulasinya adalah bahwa jika tidak dilakukan pemulihan terhadap kondisi air tanah, maka akan terjadi penambahan zona kritis dan zona rusak. Selain itu, juga terdapat penggunakan akifer tertekan yang tidak berkelanjutan, ditandai dengan muka air akifer tertekan berada di bawah batas atas lapisan. Akibat dari ekstraksi air tanah yang berlebih ini, beberapa daerah di Cekungan Bandung mengalami penurunan muka tanah. Pada tahun 2000 hingga 2012, dengan menggunakan metode GPS di beberapa tempat ditemukan penurunan muka tanah dengan rata-rata hingga $8 \mathrm{~cm} /$ tahun, dengan penurunan maksimal hingga $16.9 \mathrm{~cm} /$ tahun. Dengan metode penginderaan jauh berbasis radar, penurunan muka tanah pada periode 1999-2010 mencapai 2 meter, terutama di daerah industri; Cimahi, Katapang, Dayeuhkolot, Gedebage, dan Rancaekek (Gumilar dkk., 2015). Penelitian dari Taufiq dkk (2018) menunjukkan bahwa terdapat pencampuran antara air tanah dangkal dan air tanah dalam di beberapa tempat dicirikan oleh kandungan isotop stabil dan senyawa penjejak (tracer element).

Permasalahan airtanah di Cekungan Bandung bukan tanpa solusi. Purwoaminta dkk (2019) dalam makalahnya "Imbuhan Airtanah Buatan Untuk Konservasi Cekungan Airtanah Bandung-Soreang", meninjau mengenai upaya-upaya yang telah dilakukan untuk mengatasi permasalahan airtanah di Cekungan Bandung. Perlakuan berbeda harus diberikan antara akifer bebas dan akifer tertekan. Pada akifer bebas bisa diterapkan teknik sumur resapan, parit resapan, dan kolam resapan. Sementara pada akifer tertekan bisa diterapkan teknik sumur injeksi. Pengimbuhan air tanah telah dilakukan oleh Pemerintah Kota Bandung, Pemerintah Kota Cimahi, dan beberapa instansi. Saat ini teridentifikasi 230 sumur di wilayah Kota Bandung dan Kota Cimahi, belum termasuk di wilayah lain seperti Kabupaten Bandung dan Kabupaten Bandung Barat.

Meski ada kesimpulan yang bisa ditarik dari jumlah data yang terbatas, tetap saja jumlah makalah yang terindeks dalam basis data WoS masih sangat kurang untuk bisa membuat analisis yang representatif. Meski ada beberapa alternatif basis data lain, seperti Dimensions, namun hasil pencarian menggunakan Dimensions tidak sebaik WoS (data abstrak tidak tersedia dalam Dimensions). Pencarian menggunakan basis data lain seperti Google Scholar, meskipun menghasilkan jumlah publikasi yang lebih banyak, tetapi belum bisa digunakan karena data masih berupa data mentah yang harus dikonversi ke templat VosViewer dan belum ada cara mudah untuk melakukannya. 
Kekurangan lainnya adalah sangat banyak makalah mengenai riset di Cekungan Bandung yang belum terindeks, terutama makalah-makalah yang dipublikasikan sebelum era internet.

\section{Kesimpulan}

Dari analisis terhadap 40 publikasi mengenai air tanah di Cekungan Bandung dengan teknik bibliometrik menggunakan piranti lunak VosViewer, diketahui bahwa riset air tanah di Cekungan Bandung dapat dibagi menjadi dua kelompok besar, yaitu kelompok riset air tanah dan kelompok riset penurunan muka tanah akibat ekstraksi air tanah. Kelompok riset air tanah dapat dibagi menjadi kelompok-kelompok kecil, antara lain kelompok pemodelan akuifer, pemodelan kontaminasi, dan pemodelan pencampuran air tanah. Dari analisis terhadap judul dan abstrak makalah juga diketahui bahwa metode yang biasa digunakan dalam kelompok air tanah terutama metode pemodelan hidrogeologi, analisis hidrogeokimia, dan analisis geofisika. Sementara pada kelompok penurunan muka tanah, metode yang digunakan umumnya adalah pengukuran menggunakan GPS dan analisis citra satelit, terutama yang berbasis radar, seperti Sentinel 1, ALOS, dan ENVISAT. Jumlah metadata publikasi yang digunakan harus diakui masih sangat kurang. Pada umumnya analisis bibliometrik menggunakan ratusan, ribuan, bahkan hingga ratus ribuan makalah untuk menghasilkan data yang signifikan. Meski demikian, makalah ini dirasa dapat menggambarkan secara garis besar bagaimana riset air tanah telah berlangsung selama ini di Cekungan Bandung.

\section{Daftar Pustaka}

Abidin, H. Z., Andreas, H., Gamal, M., \& Darmawan, D. (2006). Land Subsidence Characteristics of Bandung Basin (Indonesia) between 2000 and 2005 as Estimated from GPS Surveys. 17.

Abidin, H. Z., Gumilar, I., Andreas, H., Murdohardono, D., \& Fukuda, Y. (2013). On causes and impacts of land subsidence in Bandung Basin, Indonesia. ENVIRONMENTAL EARTH SCIENCES, 68(6), 15451553. https://doi.org/10.1007/s12665-012-1848-z

Chaussard, E., Amelung, F., Abidin, H., \& Hong, S.-H. (2013). Sinking cities in Indonesia: ALOS PALSAR detects rapid subsidence due to groundwater and gas extraction. Remote Sensing of Environment, 128, 150-161. https://doi.org/10.1016/j.rse.2012.10.015

Darul, A., Irawan, D. E., \& Trilaksono, N. J. (2015). Groundwater and river water interaction on Cikapundung River: Revisited. 110007. https://doi.org/10.1063/1.4930778

Darul, Achmad, Irawan, D. E., Trilaksono, N. J., Pratama, A., \& Fitria, U. R. (2016). Conceptual model of groundwater and river water interactions in Cikapundung riverbank, Bandung, West Java. IOP Conference Series: Earth and Environmental Science, 29, 012026. https://doi.org/10.1088/17551315/29/1/012026

Du, Z., Ge, L., Ng, A. H.-M., Zhu, Q., Yang, X., \& Li, L. (2018). Correlating the subsidence pattern and land use in Bandung, Indonesia with both Sentinel-1/2 and ALOS-2 satellite images. INTERNATIONAL JOURNAL OF APPLIED EARTH OBSERVATION AND GEOINFORMATION, 67, 54-68. https://doi.org/10.1016/j.jag.2018.01.001

Ge, L., Ng, A. H.-M., Li, X., Abidin, H. Z., \& Gumilar, I. (2014). Land subsidence characteristics of Bandung Basin as revealed by ENVISAT ASAR and ALOS PALSAR interferometry. Remote Sensing of Environment, 154, 46-60. https://doi.org/10.1016/j.rse.2014.08.004

Gumilar, I., Abidin, H. Z., Hutasoit, L. M., Hakim, D. M., Sidiq, T. P., \& Andreas, H. (2015). Land Subsidence in Bandung Basin and its Possible Caused Factors. Procedia Earth and Planetary Science, 12, 4762. https://doi.org/10.1016/j.proeps.2015.03.026 
Hutasoit, L. (2009). Kondisi Permukaan Air Tanah dengan dan tanpa peresapan buatan di daerah Bandung: Hasil Simulasi Numerik. Indonesian Journal on Geoscience. https://doi.org/10.17014/ijog.vol4no3.20093

Iskandar, I., Farazi, H., Fadhilah, R., Purnandi, C., \& Notosiswoyo, S. (2017). Groundwater and solute transport modeling at Hyporheic zone of upper part Citarum River. IOP Conference Series: Earth and Environmental Science, 71, 012011. https://doi.org/10.1088/1755-1315/71/1/012011

Purwoaminta, A., Lubis, R. F., \& Maria, R. (2019). IMBUHAN AIRTANAH BUATAN UNTUK KONSERVASI CEKUNGAN AIRTANAH BANDUNG-SOREANG. Riset GeoTam, 29(1), 65-73. https://doi.org/10.14203/risetgeotam2019.v29.1004

Taufiq, A., Effendi, A. J., Iskandar, I., Hosono, T., \& Hutasoit, L. M. (2019). Controlling factors and driving mechanisms of nitrate contamination in groundwater system of Bandung Basin, Indonesia, deduced by combined use of stable isotope ratios, CFC age dating, and socioeconomic parameters. Water Research, 148, 292-305. https://doi.org/10.1016/j.watres.2018.10.049

Taufiq, A., Hosono, T., Ide, K., Kagabu, M., Iskandar, I., Effendi, A. J., ... Shimada, J. (2018). Impact of excessive groundwater pumping on rejuvenation processes in the Bandung basin (Indonesia) as determined by hydrogeochemistry and modeling. Hydrogeology Journal, 26(4), 1263-1279. https://doi.org/10.1007/s10040-017-1696-8

Taufiq, A., Hosono, T., Iskandar, I., Jatnika Effendi, A., \& Maringan Hutasoit, L. (2018). Estimating Groundwater Mixing Ratios from Vertical Flux Processes due to Excessive Groundwater Pumping Using Hydrogeochemical Parameters and Nitrate Concentrations in the Bandung Basin, Indonesia. Geologia Croatica, 71(3), 173-184. https://doi.org/10.4154/GC.2018.19

van Eck, N. J., \& Waltman, L. (2010). Software survey: VOSviewer, a computer program for bibliometric mapping. Scientometrics, 84(2), 523-538. https://doi.org/10.1007/s11192-009-0146-3

Waaijer, C. J. F., \& Palmblad, M. (2015). Bibliometric Mapping: Eight Decades of Analytical Chemistry, With Special Focus on the Use of Mass Spectrometry. Analytical Chemistry, 87(9), 4588-4596. https://doi.org/10.1021/ac5040314 